\title{
CARACTERÍSTICAS FÍSICAS, QUÍMICAS E ISOTÓPICAS DAS ÁGUAS SUBTERRÂNEAS DE ÁGUAS DE LINDÓIA E LINDÓIA - REVISÃO.
}

\author{
Joaquim Ernesto Bernardes Ayer ${ }^{1}$; Waldilene dos Santos Corrêa ${ }^{1} \&$ Sueli Yoshinaga Pereira ${ }^{1}$
}

Resumo - As águas que compõem o ciclo hidrológico são transportadas, armazenadas e distribuídas dentro das diferentes esferas, das rochas, dos solos, do ar, da biosfera e nos próprios corpos de água. Neste ciclo, as águas irão passar por diversas alterações físico-químicas, em função das características biofisiográficas e hidrogeológicas locais. Com o objetivo de compilar e discutir a questão hidrogeológica nos municípios de Águas de Lindoia e Lindoia - SP, foi realizado a revisão da literatura e organização de dados sobre composição física, química e isotópica destas águas. Destes dados, foi realizado em Sistemas de Informação Geográfica a interpolação e espacialização de dados físico-químicos da área, visando traçar um panorama sobre as condições de circulação dos aquíferos fraturados do Circuito das Águas Paulistas. Os dados isotópicos da área, indicam que as mesmas são de infiltração recente, e que as mesmas sofrem processos de concentração isotópica, resultado da interação com a geologia e pedologia. A hidroquímicas na área e caracterizada por águas pouco mineralizadas, classificadas como bicabornatadas mistas ou cálcicas de boa potabilidade. Porém, devido seu fluxo rápido e baixo tempo de residência, os aquíferos locais, devem ser constantemente avaliados, para evitar sua contaminação, visto, a ocupação antrópica próxima das áreas de explotação.

\begin{abstract}
The waters that make up the hydrological cycle are transported, stored and distributed within the different spheres of rocks, soil, air, and biosphere own bodies of water. In this cycle, the water will pass through several physicochemical changes, depending on the hydrogeological features and biofisiográficas locations. In order to compile and discuss the issue in the municipalities of hydrogeological Lindoia Waters and Lindoia - SP, was conducted the literature review and organization of data on physical composition, chemical and isotopic these waters. From these data, it was held in Geographic Information Systems interpolation and spatial distribution of deuterium isotope data and Oxygen 18, aiming to give an overview of traffic conditions of fractured aquifers of the Circuit of Water Paulistas. The isotopic data from the area indicate that they are of recent infiltration, and that they suffer processes of isotopic concentration as a result of interaction with the geology and soil science. The hydrochemical area and characterized by low mineralization,


classified as mixed or calcic bicabornatadas good drinkability. However, due to its fast and low flow residence time, local aquifers should be constantly evaluated to prevent contamination, as the next human occupation of areas of exploitationmineralized, and are low residence, result of hydrodynamic characteristics of the local aquifers, They shouldnt be Evaluated Constantly, to avoid contamination of These resources. The low residence, result of hydrodynamic characteristics of local aquifers, they should be constantly evaluated, to avoid contamination of these resources.

Palavras-Chave - Circuito das Águas Paulistas, Hidrogeologia, Aquífero Fissurado.

\section{1 - INTRODUÇÃO}

As águas que compõem o ciclo hidrológico são transportadas, armazenadas e distribuídas dentro das diferentes esferas, das rochas, dos solos, do ar, da biosfera e nos próprios corpos de água. Neste ciclo, desde a evaporação das águas nos oceanos, seu transporte pelas massas de ar, sua precipitação, evapotranspiração, escoamento superficial e subterrâneo nos continentes até sua volta aos oceanos, as águas irão passar por diversas alterações físico-químicas. Estas, serão em função do tipo e do tempo residência nestes reservatórios e serão diretamente dependentes dos tipos dos fluxos, formas dos reservatórios, e origem das águas meteóricas, Fetter (1994).

O fluxo e o armazenamento das águas depende da profundidade do escoamento e são armazenadas de três formas principais, são elas: i) podem escoar na superfície e subsuperfície, seguindo as orientações do relevo, com fluxo rápido e livre e com águas recentes; ii) elas podem escoar em profundidades intermediárias em aquíferos livres com fluxos heterogêneos dependendo do tipo de matriz e idades relativamente recentes; e iii) podem fluir em aquíferos confinados e profundos com fluxo lento e tempo de residência longo (FETTER, 1994).

Para determinar a proveniência das águas, tradicionalmente é determinado o nível piezométrico da água, sendo as transmissividades, determinadas por ensaios de bombeamento. Porém, este método não possibilita avaliar a origem e idade das águas, o que pode ser em partes solucionada pela avaliação dos isótopos ambientais. Estes, permitem definir a proveniência das águas armazenadas. A partir da análise da concentração de massa de isótopos leves e pesados, podemos definir se estas provêm das chuvas meteóricas, também denominadas de águas leves de idades modernas, ou se são águas profundas de aquíferos confinados, denominadas águas minerais de idades quaternárias (Fetter, 1994; Clark e Fritz, 1997). A utilização dos isótopos ambientais é uma potente ferramenta, visto que sua concentração natural está ligada às características do meio, o que permite seu uso como marcador cronológico (CLARK \& FRITZ, 1997). 
Segundo UNFPA, 2013, o consumo de água tem aumentado nos últimos anos, assim como a contaminação dos recursos hídricos de fácil acesso, como as águas doces superficiais e subterrâneas de baixa profundidade. Existe ainda uma tendência de crescimento da população e da demanda direta por água; do seu consumo indireto para produção de commodities da agropecuária; e de bens de consumo industrializados (UNFPA, 2013), que deverão acarretar ainda maior pressão sobre as águas. Além disso, no Brasil, 79,6 \% da energia consumida é hidrelétrica (BRASIL, 2013), e para produção do Etanol e do Biodiesel, outras matrizes energéticas, também são dependentes de consumo de água. Desta forma, avaliar os condicionantes ambientais que vão influenciar os recursos hídricos é importante (Carvalho, 2008). A ação antrópica tem alterado o equilíbrio natural entre os fluxos superficiais e subterrâneos, além de afetar seus atributos físicos e químicos (Brady e Weil, 2013). De fato, as águas subterrâneas podem não ser renováveis na escala de tempo humana. A disposição inadequada de resíduos industriais e o manejo convencional da agropecuária, com uso de agroquímicos e mecanização nas lavouras, têm resultado aumento da contaminação e perda de água, de nutrientes, de solos e de carbono (MORGAN e NEARING, 2011; AYER et al., 2013).

Dentro deste contexto, a região do Circuito Paulista das Águas sofre pela degradação e ausência de áreas de preservação permanente e manejos conservacionistas do solo. Esta área possui apenas cerca de $7 \%$ da cobertura vegetal nativa, o que acaba refletindo na alteração do equilíbrio ecossistêmico e na qualidade das águas (Fundação SOS Mata Atlântica e INPE, 2013). Todavia, a economia destes municípios é em grande parte baseada na exploração da água, seja de maneira direta no envasamento de água mineral, ou de forma indireta, como atrativo turístico. Devemos destacar que o Estado de São Paulo é o maior produtor nacional de água mineral com $17 \%$ da produção, sendo que estes municípios respondem por 30\% do total estadual (DNPM, 2013). Deste modo, o recente quadro de escassez de água na região sudeste do Brasil, demonstra o quanto a falta de gestão, associada à poluição tem comprometido os recursos hídricos e tornado esta região suscetível a impactos socioeconômicos e ambientais deletérios, evidenciados devido às variações no clima. Apesar desse quadro, as rochas cristalinas fraturadas, podem apresentar grande potencial para a acumulação de água, pois demonstra uma relativa abundância e utilização de água dos aquíferos da região do Circuito das Águas Paulista (DAEE, 2005).

De tal modo, o objetivo deste estudo foi de compilar e discutir a questão hidrogeológica nos municípios de Águas de Lindoia e Lindoia - SP. Para isto, foi realizado a revisão da literatura para aquisição de dados sobre composição física, química e isotópica destas águas, no intuito de traçar um panorama sobre as condições dos aquíferos fraturados do Circuito das Águas Paulistas. 


\section{2 - MATERIAIS E MÉTODOS}

Os municípios de Águas de Lindoia e Lindoia localizados no Circuito das Águas Paulista é uma região com extensas reservas de água subterrânea, mostrando assim potencial de armazenamento desse recurso natural. Localizada na região central da província da Mantiqueira sob as respectivas coordenadas, $22^{\circ} 28^{\prime} 44,60^{\prime \prime} \mathrm{S} ; 46^{\circ} 37^{\prime} 42,47^{\prime \prime} \mathrm{W}$ e $22^{\circ} 36^{\prime} 44^{\prime \prime} \mathrm{S}$ e $46^{\circ} 42^{\prime} 02^{\prime \prime} \mathrm{W}$, possui clima Tropical Mesotérmico ou Tropical de Altitude (Cwa), segundo a classificação de Köppen (Sparovek et al., 2007). Está inserida no domínio do bioma Mata Atlântica, apresentado somente 6\% de cobertura vegetal nativa (Fundação SOS Mata Atlântica e INPE, 2013).

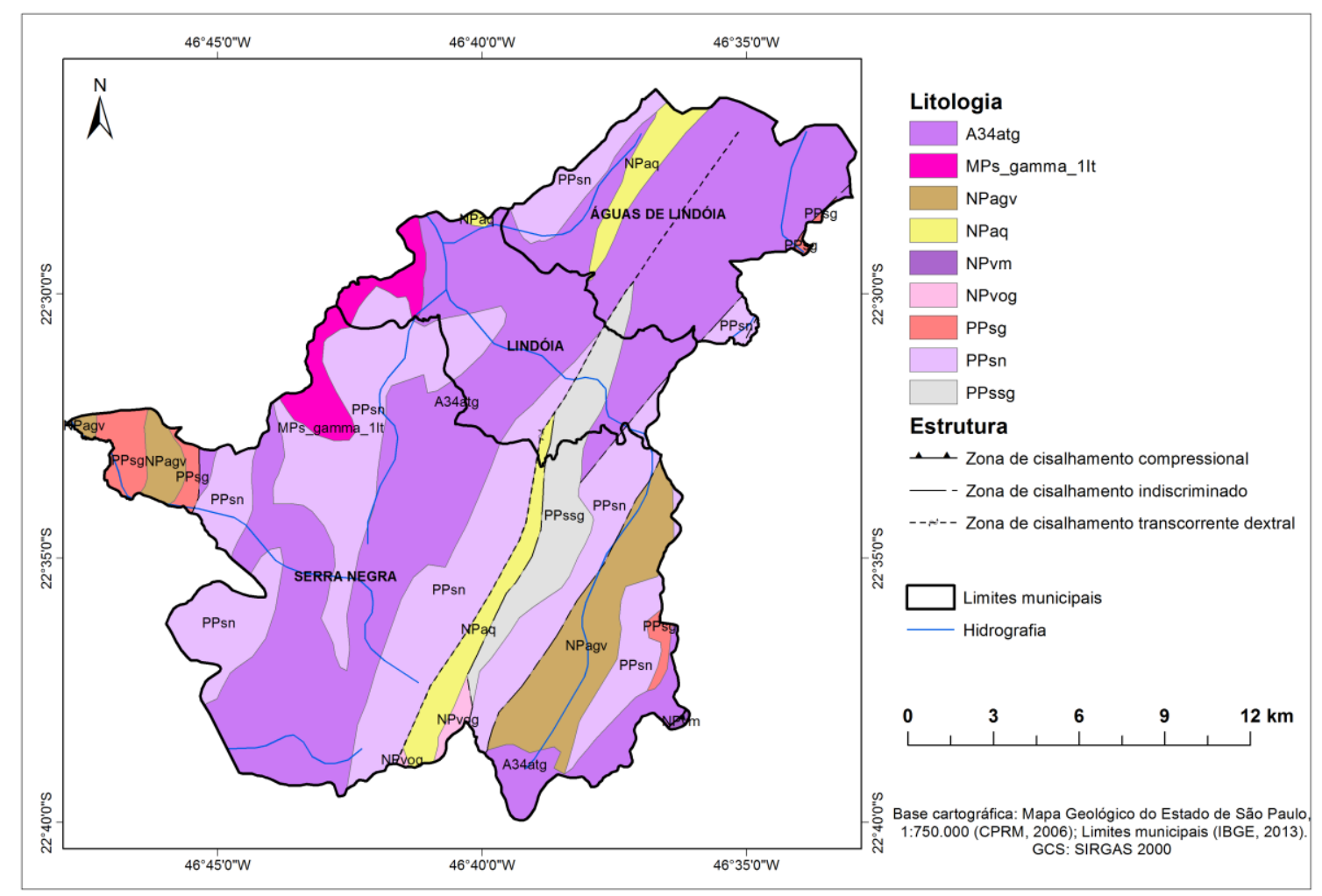

Figura 1: Mapa de localização e geologia

Foram realizados estudos preliminares com a revisão da bibliografia especializada, para aquisição de dados hidrogeológicos físicos, químicos e isotópicos dos aquíferos fraturados do Circuito das Águas Paulista. Foram utilizados os dados de ${ }^{18} \mathrm{O}$, Deutério, PH e transmissividade, coeficiente hidráulico, composição química e litologia do poço de Yoshinaga, (1990); Isótopos de Urânio (U) de Silveira e Bonoto (1995), Geologia de Madrucci (2005 e 2008) e isótopos de Rádio (Ra) de Negão (2012) entre outros.

Os dados de Oxigênio 18 e Deutério foram tabulados, no Excel e depois foram plotados a partir de suas coordenadas geográficas, no sistema de informação geográfica da plataforma ArcGIS, no qual foi realizado o georreferenciamento e a espacialização destes valores a partir do interpolador IDW. O interpolador IDW utiliza o modelo estatístico do "Inverso das Distâncias", e baseia-se na dependência espacial, isto é, supõe que quanto mais próximo estiver um ponto do outro, maior 
deverá ser a correlação entre seus valores. Dessa forma, atribui maior peso para as amostras mais próximas do que para as amostras mais distantes do ponto à ser interpolado. Assim o modelo consiste em se multiplicar os valores das amostras pelo inverso das suas respectivas distâncias ao ponto de referência. Finalmente, foi feita a discussão destes dados geoespaciais, buscando apontar quais fatores ambientais, podem influenciar a hidrogeologia local.

Foi também gerado o Índice de Vegetação da Diferença Normalizada (NDVI - Normalized Difference Vegetation Index) para área. Este é obtido a partir da razão entre a diferença da reflectância do infravermelho próximo (NIR) e do vermelho (VIS), sendo essa diferença normalizada pela divisão da soma das faixas de NIR e VIS (ROUSE et al., 1973). O mapa de índice de vegetação foi gerado a partir da ferramenta NDVI da extensão Image Analysis do software ArcGIS 10.2. Foram utilizadas as bandas 3 (VIS) e 4(NIR) do TM/ Landsat-5, Cena 219/76 para a respectiva data das informações medidas para os poços.

Por fim foi criada uma representação atribuindo cores a determinados intervalos do NDVI, definidos pelo classificador Quebras-Naturais. Posteriormente, cada intervalo foi associado à uma ou mais classe de uso do solo e cobertura vegetal.

\section{1 - Breve histórico da utilização de isótopos na hidrogeologia}

Segundo IAEA (2001), isótopos são elementos químicos que possuem número atômico igual e número de massa diferente. Esta diferença no número de massa é provocada pela variação do número de nêutrons do elemento e condiciona comportamentos distintos do elemento. $\mathrm{O}$ emprego de isótopos ambientais, assim denominados por serem encontrados de forma generalizada no meio ambiente, é devido à concentração local e a abundância relativa entre os vários isótopos. Os isótopos podem ser radioativos (estarem sujeitos a desintegração no tempo por emissão de radioatividade) ou não. As concentrações de isótopos podem variar ainda pela maritimidade ou continentalide, pela, latitude e altitude, profundidade dos poços, pelas mudanças de fases ou estados, alterações nas taxas de reação química e diferenças na velocidade de difusão molecular.

A aplicação de isótopos ambientais surgiu no final da década de 1940, sendo os primeiros estudos realizados por Urey, (1947), e Epstein (1951) in Silveira e Silva Junior (2002). Atualmente, a aplicação de isótopos já está bastante difundida, com protocolos e métodos bem estabelecidos. No Brasil, os primeiros estudos datam das décadas de 1960 e 1970 e foram motivados, devido necessidade de compreender os aquíferos do Nordeste, que estavam sendo salinizados, assim como os regimes das águas e rios no Norte. Posteriormente, surgiram estudos no Sudeste principalmente na região do Aquífero Botucatu, atualmente existem bastantes estudos sobre isótopos no Brasil, 
todavia, há ainda uma gigantesca necessidade de estudos deste tipo no país, vista a riqueza hidrológica nacional (SILVEIRA e SILVA JUNIOR, 2002)

As determinações de isótopos são bastante intrincadas e são poucos os laboratórios no mundo que podem realizá-las. Porém, felizmente, as diferenças de concentrações entre estes isótopos são mais facilmente determinadas através da aferição da diferença relativa destes em um espectrômetro de massa. Esta conexão inversamente proporcional entre as concentrações isotópicas $(\delta)$, equação 1, é expressa, em partes por mil (\%), resultado da razão medida na amostra e a razão medida em um padrão de referência internacional (antigamente SMOW - Standard Mean Ocean Water e atualmente VSMOW - Viena Standard Mean Ocean Water), medidos concomitantemente no mesmo aparelho e expressos, como no exemplo do cálculo para o ${ }^{18} \mathrm{O}$ na Equação 1 , (CLARK \& FRITZ, 1997):

$$
\delta{ }^{18} \mathrm{O}_{\text {amostra }}=\left({ }^{18} \mathrm{O} /{ }^{16} \mathrm{O}\right)_{\text {amostra }}-\left({ }^{18} \mathrm{O} /{ }^{16} \mathrm{O}\right)_{\text {padrão }} /\left({ }^{18} \mathrm{O} /{ }^{16} \mathrm{O}\right)_{\text {padrão }}
$$

Em que: $\quad \delta^{18} \mathrm{O}_{\text {amostra }}$ é a concentração isotópica em partes por mil de ${ }^{18} \mathrm{O}$ na amostra

$\left({ }^{18} \mathrm{O} /{ }^{16} \mathrm{O}\right)$ amostra é a razão relativa entre ${ }^{18} \mathrm{O}$ e ${ }^{16} \mathrm{O}$ na amostra

$\left({ }^{18} \mathrm{O} /{ }^{16} \mathrm{O}\right)$ padrão é a razão relativa entre ${ }^{18} \mathrm{O}$ e ${ }^{16} \mathrm{O}$ no padrão internacional.

Os estudos com isótopos ambientais utilizam principalmente os isótopos naturais que seguem os ciclos geoquímicos dos elementos, e os mais utilizados são os de hidrogênio $\left({ }^{1} \mathrm{H},{ }^{2} \mathrm{H}\right.$, ${ }^{3} \mathrm{H}$ ), carbono $\left({ }^{12} \mathrm{C},{ }^{13} \mathrm{C},{ }^{14} \mathrm{C}\right)$, nitrogênio $\left({ }^{14} \mathrm{~N},{ }^{15} \mathrm{~N}\right)$, oxigênio $\left({ }^{16} \mathrm{O},{ }^{18} \mathrm{O}\right)$ e enxofre $\left({ }^{32} \mathrm{~S},{ }^{34} \mathrm{~S}\right)$, todavia, diversos outros isótopos podem ser utilizados, como por exemplo o ${ }^{234} \mathrm{U}$ e ${ }^{238} \mathrm{U}$, e ${ }^{226} \mathrm{Ra}$ e ${ }^{228} \mathrm{Ra}$, aplicados nos estudos de Silveira e Bonoto (1995) e Negão (2012).

Naturalmente os isótopos possuem uma concentração baixa, porém, algumas atividades antrópicas afetaram essa distribuição. A explosão de bombas nucleares, principalmente durante a corrida armamentista na década de 1950, aumentou a concentração dos isótopos de hidrogênio. Apesar disso, o aumento da concentração de isótopos de hidrogênio permite identificar águas com idades de até 65 anos (IAEA, 2001)

A composição isotópica é afetada, pela alteração da concentração gerada pelos processos de evaporação, uso pelas plantas, mudanças climáticas e reações com o solo/rocha. (CLARK \& FRITZ, 1997). Com a utilização de estudos de todo o mundo, foram traçadas retas de água meteórica, que representam a concentração destes isótopos nas diferentes regiões. Assim, é possível a partir do conhecimento das entradas atmosféricas determinar quais processos são responsáveis pela alteração no fracionamento destes em subsuperfície. Atualmente a Agência Internacional de 
Energia Atômica (OIEA) mantém um banco de dados mundial da concentração destes isótopos na atmosfera. Além da reta meteórica mundial, existem, embora às vezes sem uma boa série histórica, as retas meteóricas locais, como no caso do Brasil que possui as retas de São Gabriel, Belém, Manaus, Fortaleza, Benjamin Constant, Ceará Mirim, Porto Velho, Salvador, Cuiabá, Brasília, Rio de Janeiro e Porto Alegre. Águas que estão acima da reta são consideradas águas mais antigas ou quaternárias, e as águas que tem distribuição abaixo da linha são consideradas águas modernas ou recentes.

\section{3 - RESULTADOS E DISCUSSÃO}

\section{1 - Características hidrogeológicas e naturais regionais}

A área está localizada na região central da província da Mantiqueira. A geologia da área é bastante complexa com rochas muito antigas, que devido aos múltiplos ciclos e fases metamórficas, ígneas, migmatíticas e cataclásticas, tornam difícil o processo de investigação geológica. Todavia, estas têm como características marcantes, a presença de rochas de alto grau metamórfico, de idades variadas e com alta variação de granulação, que foram submetidas a eventos que atuaram desde o arqueano até o Proterozóico superior. A geologia da região é composta de rochas mais antigas do Grupo Amparo, migmatíticas, gnáissicas e graníticas, e por rochas metassedimentares como quartzitos e ortoquartzitos do Grupo Itapira, que são extremamente fraturadas em função de seu comportamento rúptil, o que favorece a circulação de água subterrânea. A Zona de Cisalhamento Monte Sião (Figura 1) corta a região em sua porção central, com direção NNE para SSW (ALMEIDA e HASUI, 1984; MADRUCCI et al., 2005; HASUI, 2010).

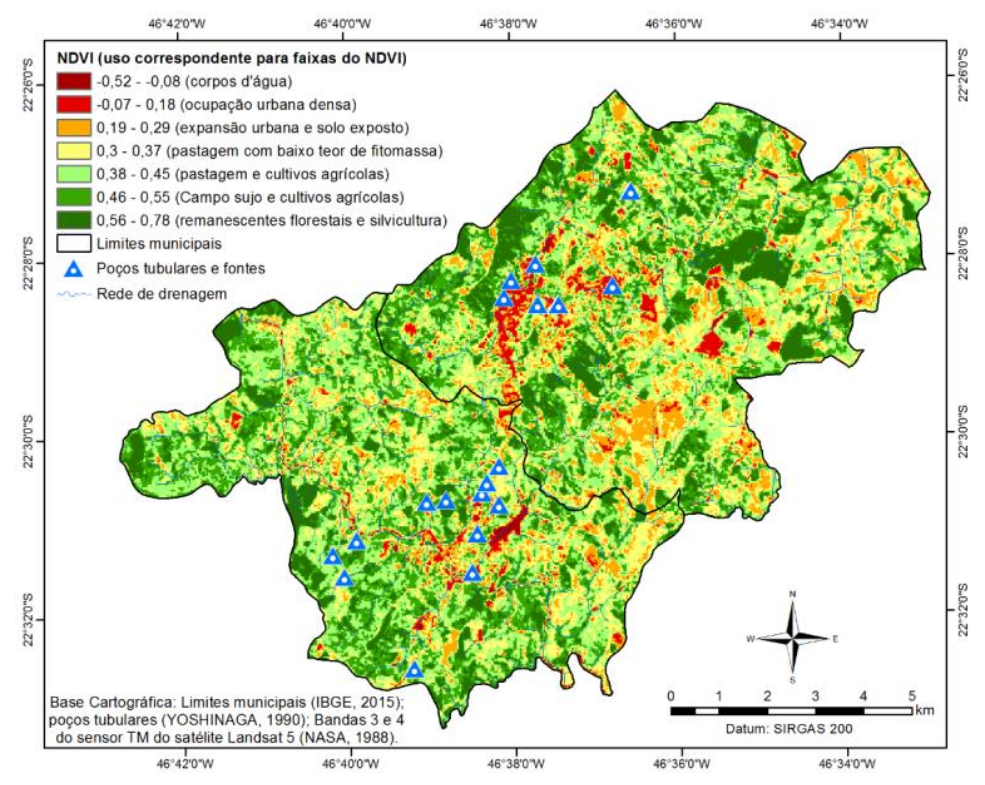

Figura 2: Mapa do índice de vegetação - NDVI 
É visível na figura 2, que nas áreas de maiores quantidades poços, há maior conservação dos fragmentos de mata, mas também há maior ocupação urbana. De tal modo, isto contribui para manutenção da qualidade das águas, mas as deixa mais suscetível a contaminação por agentes antrópicos, daí a necessidade de monitoração destes recursos.

A grande densidade de fraturas nas rochas, favorece a circulação da água e diminui o tempo de residência na mesma (MADRUCCI et al., 2005; YOSHINAGA, 1990). Yoshinaga e colaboradores (1990), avaliaram a concentração de isótopos ambientais do Oxigênio 18 e de Deutério nas águas meteóricas e subterrâneas. Segundo estes dados, algumas das águas subterrâneas apresentam composição isotópica bem parecida com as das águas meteóricas, o que denota uma correlação isotópica entre estas águas. Daí sua classificação como águas levíssimas.

Segundo Yoshinaga (1990), os valores mais frequentes de capacidade específica estão situados no intervalo de $9,0 \times 10^{-6}$ a $2,2 \times 10^{-4} \mathrm{~m}^{3} / \mathrm{s} / \mathrm{m}(88 \%)$, com mediana de $3,8 \times 10^{-5} \mathrm{~m}^{3} / \mathrm{s} /$ m. Ainda, segundo Yoshinaga (1990), a região apresenta transmissividades expressivas, entre, 1,2 x $10^{-4} \mathrm{~m}^{2} / \mathrm{s}, 3,1 \times 10^{-4} \mathrm{~m}^{2} / \mathrm{s}, 3,6 \times 10^{-4} \mathrm{~m}^{2} / \mathrm{s}$ e $12,8 \times 10^{-4} \mathrm{~m}^{2} / \mathrm{s}$.

Porém, dependendo da litologia e das morfoestruturas, (topo, vertente, várzea) os valores de capacidade específica e transmissividade variam. Sendo que os poços em quartzitos apresentaram maiores valores, enquanto os poços em migmatito os valores foram menores e no migmatito milonitizado foram os menores de todos. Além disto, poços localizados nas várzeas, apresentaram maiores valores de capacidade específica e transmissividade (YOSHINAGA, 1990).

A tendência de maior produção de água nos quartzitos em comparação aos migmatitos, pode ser atribuída aos planos de foliação bem desenvolvidos e a maior ruptibilidade, que resultam em fraturamentos extensos e abertos. Além de que o material arenoso de maior permeabilidade gerado da alteração do quartzito, pode influir na produtividade dos poços, pois conduz a água com maior eficiência quando comparado ao material argiloso produzido pelo migmatito (YOSHINAGA, 1990).

Além disto, a região apresenta um manto alteração com média de 33 metros nos topos, 16,8 nas vertentes e 24,6 nos vales e valor máximo de até 60 metros. Esta situação favorece o desenvolvimento dos solos, e o fluxo de águas subterrâneas. Destas características resultaram um relevo bem dissecado, com predomínio de três tipos principais de formações geomorfológicas, as serras alongadas NE-SW, com encostas íngremes; os morros arredondados em conjunto as serras, além do relevo característico dos mares de morros, com presença de vales mais amplos, solos mais profundos e planícies aluvionares mais desenvolvida. Os solos da região são bastante diversificados, 
visto a complexa geomorfologia da área, contudo há predomínio de Latossolos distróficos, Argissolos, Cambissolos e Gleissolos nas áreas de várzea (IAC, 1999)

\section{2 - Hidroquímica}

As chuvas amostradas por Yoshinaga (1990), apresentaram condutividade elétrica, entre 3 e $51 \mu \mathrm{S} / \mathrm{cm}$; teores em mg/l de cálcio entre 0,04 e 3,53; magnésio no intervalo de 0,1 a 0,56; teor de sódio variando de 0,20 a 0,48; potássio entre 0,04 e 0,44 ; cloreto entre 0,07 e 2,84, nitrato entre 0,01 e 3,31 e de sulfato com valores entre 0,02 e 7,05.

A variação das concentrações de íons pode ser atribuída a fatores como, intensidade frequência e duração das precipitações, época do ano, condições climáticas e topografia. Sendo que os íons dominantes foram o $\mathrm{Ca}^{2+}, \mathrm{K}^{+}, \mathrm{Mg}^{2+} \mathrm{e} \mathrm{SO}_{4}{ }^{2-}$, o que é comum em regiões continentais. Nos períodos de inverno e outono as chuvas tendem a ter uma maior salinidade, sendo estes teores menores no verão (YOSHINAGA, 1990).

No estudo de Yoshinaga (1990), as concentrações de oxigênio 18 e deutério nas águas de chuvas foram muito similares as das retas meteóricas mundiais e próximos a reta meteórica para a América do Sul. As chuvas apresentaram média de -5,27 \%o (SMOW), figura 3, para uma precipitação de 1810,7 mm. Esta negatividade pode ser explicada pelas altas taxas de precipitações e também pelo efeito da altitude e a grande distância do oceano.

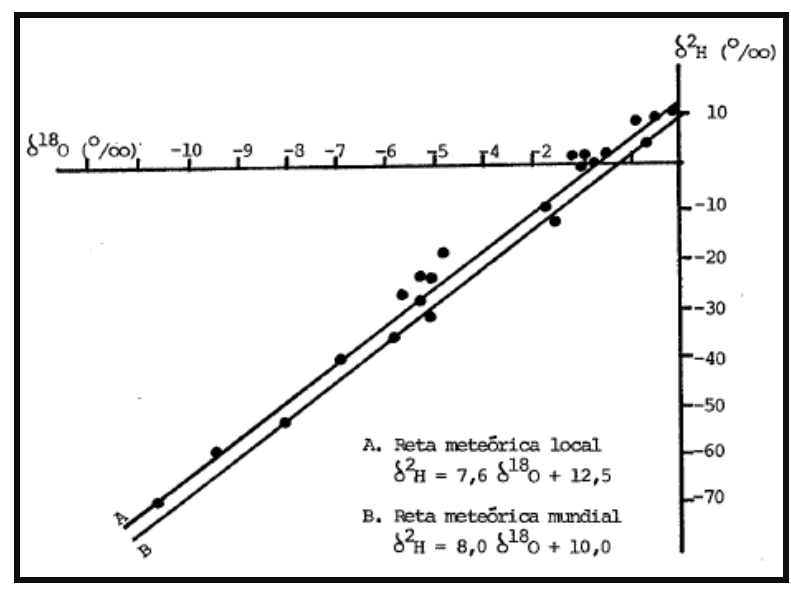

Figura 3: Relação entre as $\delta{ }^{18} \mathrm{O}$ e $\delta{ }^{2} \mathrm{H}$, das águas de chuva com a reta meteórica mundial. Fonte: Yoshinaga, (1990).

As águas de fontes e poços tubulares têm como características a baixa condutividade elétrica (figura 4), entre 9 us/cm a $165 \mathrm{uS} / \mathrm{cm}$; pH entre 5 a 7,70 (figura 5) e Eh no intervalo de 13 $\mathrm{mV}$ a $125 \mathrm{mV} ; \mathrm{CO}_{2}$ livre entre zero $68,2 \mathrm{mg} / 1$ e temperatura entre $18^{\circ}$ e $28^{\circ} \mathrm{C}$ (YOSHINAGA, 1990).

Todavia, quando comparamos fontes e poços, provenientes de migamatitos e de quartztos, estas tendem ter valores médios menores de condutividade $(74,82 \mathrm{uS} / \mathrm{cm})$ e de $\mathrm{CO}_{2}$ livre $(17,15$ 
$\mathrm{mg} / \mathrm{l})$, e possuem $\mathrm{pH}$ mais básico em tono de 6,61 e temperatura média mais elevada $\left(23^{\circ} \mathrm{C}\right)$, enquanto os migmatitos milonitizados têm valores médios de condutividade de $83,50 \mathrm{uS} / \mathrm{cm}, \mathrm{CO}_{2}$ livre de 44,83 mg/l, com o pH e Eh com valores médios de 5,84 e 66,25 mV. Já os migmatitos, apresentam os maiores valores de condutividade média $(91,83 \mathrm{uS} / \mathrm{cm}, \mathrm{pH}$ mais ácido $(5,6)$, Eh médio de $80,33 \mathrm{mV}$, menor temperatura média $\left(21^{\circ} \mathrm{C}\right)$ e teor de $\mathrm{CO}_{2}$ livre de $42,35 \mathrm{mg} / \mathrm{l}$ (YOSHINAGA, 1990).

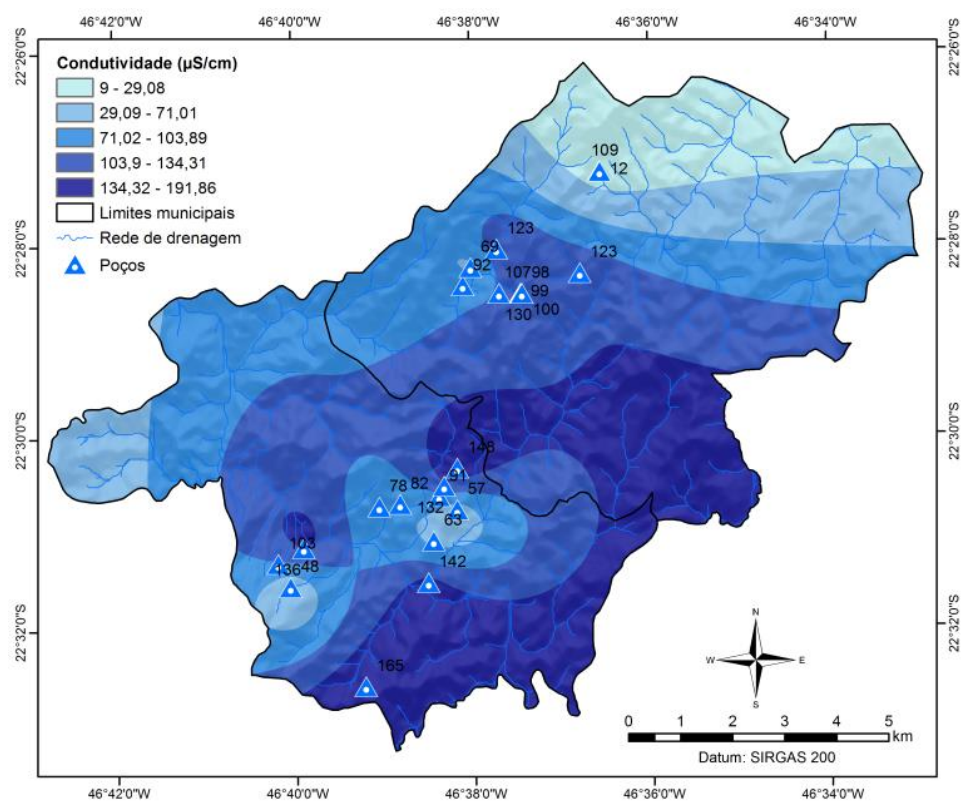

Figura 4: Mapa de condutividade elétrica (adaptado de Yoshinaga, 1990).

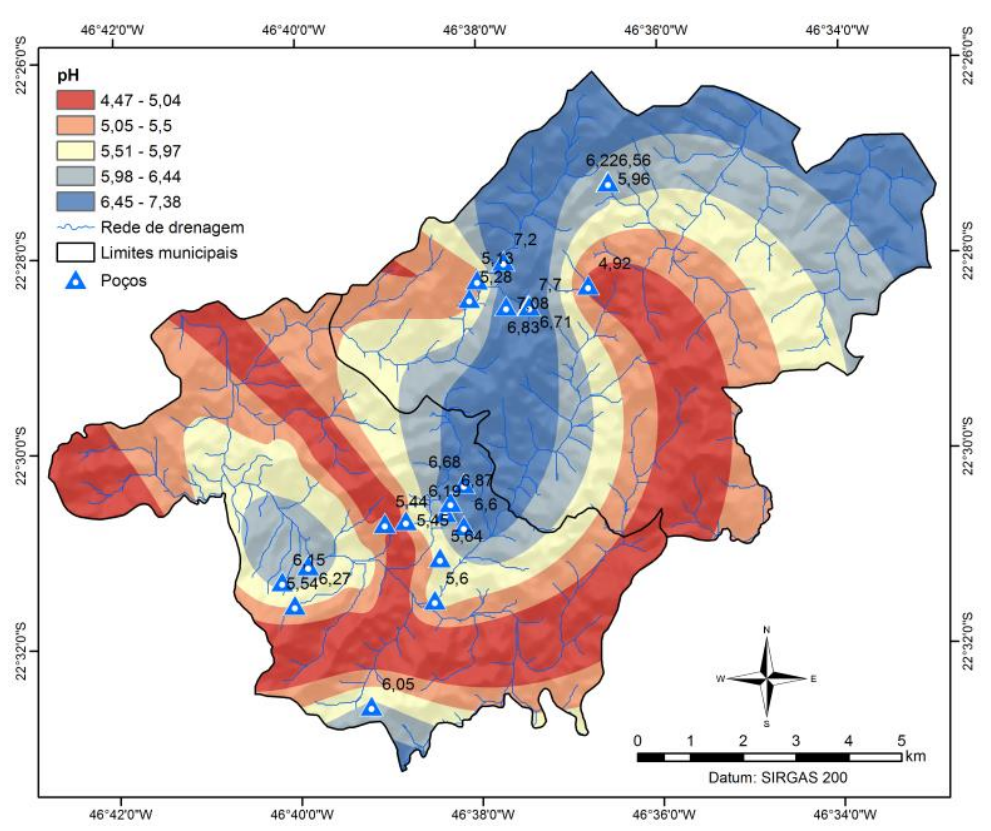

Figura 5: Mapas de Isótopos de hidrogênio (adaptado de Yoshinaga, 1990). 
No geral ás aguas das fontes são puco mineralizadas, sendo que os íons dominantes foram respectivamente os de $\mathrm{Ca}^{2+}, \mathrm{K}^{+}, \mathrm{Mg}^{2+} \mathrm{e} \mathrm{SO}_{4}{ }^{2-}$, já o cloreto o sulfato e o nitrato apresentaram baixas concentrações (YOSHINAGA, 1990).

As águas apresentam, ainda segundo Silveira e Bonoto (1995) e Negão (2012) minerais radioativos, resultados da desintegração dos elementos Rádio 226 e Urânio, presente nas rochas, em gás radônio 222, e complexos de Urânio - $\mathrm{UO}_{2} \mathrm{CO}_{3}{ }^{0}$ e $\mathrm{UO}_{2}\left(\mathrm{CO}_{3}\right)^{2} 2$

Segundo Negão (2012) as concentrações médias aritméticas variaram de $4,8 \mathrm{mBq} \mathrm{L}^{-1}$ a 41 $\mathrm{mBq} \mathrm{L}-1$ e de $30 \mathrm{mBq} \mathrm{L}^{-1}$ a $54 \mathrm{mBq} \mathrm{L}^{-1}$ para ${ }^{226} \mathrm{Ra} \mathrm{e}{ }^{228} \mathrm{Ra}$, respectivamente. O maior valor de atividade de ${ }^{226} \mathrm{Ra}$ foi observado nas águas da Fonte Engarrafada São Jorge, enquanto que a concentração máxima de ${ }^{228} \mathrm{Ra}$ foi determinada na Fonte Santa Filomena. As razões de atividade ${ }^{228} \mathrm{Ra} /{ }^{226} \mathrm{Ra}$ variaram de 1,2 (Fonte Engarrafada São Jorge) a 9,1 (Fonte Engarrafada Jatobá 1). De acordo Silveira e Bonoto (1995) as águas apresentam ainda pequenos teores de minerais de Urânio dissolvido nas águas subterrâneas que variaram de 0,001 a 0,509 ppb, enquanto que a razão de atividade $234 \mathrm{U} / 238 \mathrm{U}$ para as fontes estudadas situou-se entre 0,81 e 3,76.

Em geral, a composição química das águas possuem as seguintes concentrações de íons prinicipais (med/l): $\mathrm{rCa}>\mathrm{rMg}>\mathrm{rK}$ e $\mathrm{r} \mathrm{HCO}_{3}>\mathrm{rCl} \approx \mathrm{rNO}_{3}>\mathrm{rSO}_{4}$. Segundo Yoshinaga (1990) as águas são classificadas de acordo com o diagrama de Piper, em sua maioria como Bicarbonatadas cálcicas e bicarbonatadas cálcio-magnesianas, e as das fontes Levíssima 1 e 2 e nossa Senhora das Brotas como bicarbonatadas sódicas e as fontes sertãozinho e da pracinha como cloretadas sódicas (YOSHINAGA, 1990).

A circulação das águas nos solos, promovem processos de mineralização, devido aos seu enriquecimento em ácidos orgánicos, derivados da materia orgânica. Esta água enriquecida pelo gás $\mathrm{CO}_{2}$ altera a equação do equilíbrio do $\mathrm{CO}_{2}$, provocando a dissociação do ácido carbônico, formando bircabonato. De tal modo, o aumento da concentração de $\mathrm{H}^{+}$inibe a formação de carbonatos, a níveis mínimos indetectáveis, como nas águas análisadas. Essa água intensifica os processos de alteração do minerais das rochas através da hidratação principlamente pela hidrólise (YOSHINAGA, 1990).

As rochas da área investigada apresentam os seguintes constituintes minerais: plagioclásios $\left(\mathrm{Ca}_{\mathrm{n}}(\mathrm{Na})_{\mathrm{m}} \mathrm{AlSi}_{3} \mathrm{O}_{8}\right)$, ortoclásio $\left(\mathrm{KAlSi}_{3} \mathrm{O}_{8}\right)$, Biotita $\left(\mathrm{H}_{2} \mathrm{~K}(\mathrm{Mg}, \mathrm{Fe})_{3} \mathrm{Al}\left(\mathrm{Si}_{4}\right)_{3}\right.$, hornblenda (( $\mathrm{Ca}$, $\left.\left.\mathrm{Na})_{2-3}(\mathrm{Mg}, \mathrm{Fe}, \mathrm{Al})_{5}(\mathrm{Si}, \mathrm{Al}) \mathrm{Si}_{3} \mathrm{O}_{11}\right)_{2}(\mathrm{OH})_{2}\right)$ ) e muscovita $(\mathrm{H}, \mathrm{K}) \mathrm{AlSiO}_{4}$. A alteração deste minerais fornece a água elementos como, cálcio, magnésio, ferro e potásio (YOSHINAGA, 1990). Os processos mais intensos de mineralização nesta região ocorrem no manto de alteração, onde a água que se infiltra, ataca os minerais pela hidólise e se enriquece em íons. Sendo as águas dos poços 
mais mineralizadas do que as das fontes em função dos maiores tempos de residencia e profundidade.

$\mathrm{Na}$ área de investigação os teores de oxigênio 18 (Figura 5), das águas das fontes e poços variaram de $-8,30 \%$ a $-6,80 \%$. As concentrações de deutério foram de $-51,8 \%$ oa -45,7\%o, como demonstra a figura 7.

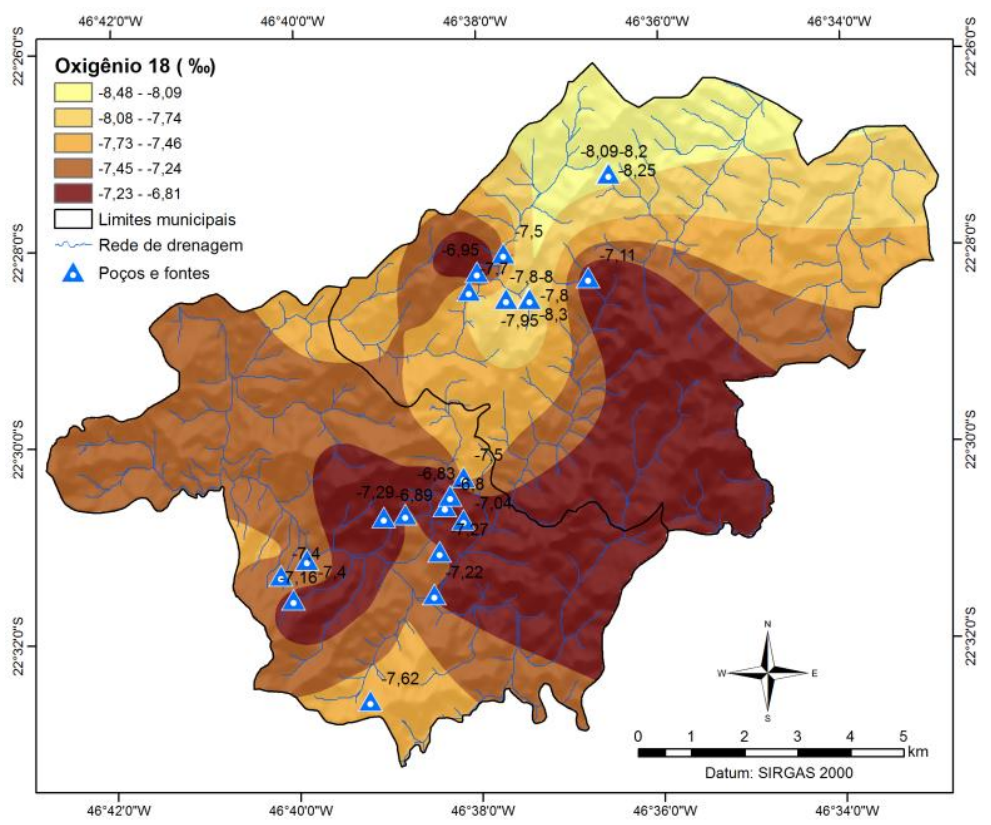

Figura 6: Mapas de Isótopos de oxigênio (adaptado de Yoshinaga, 1990).

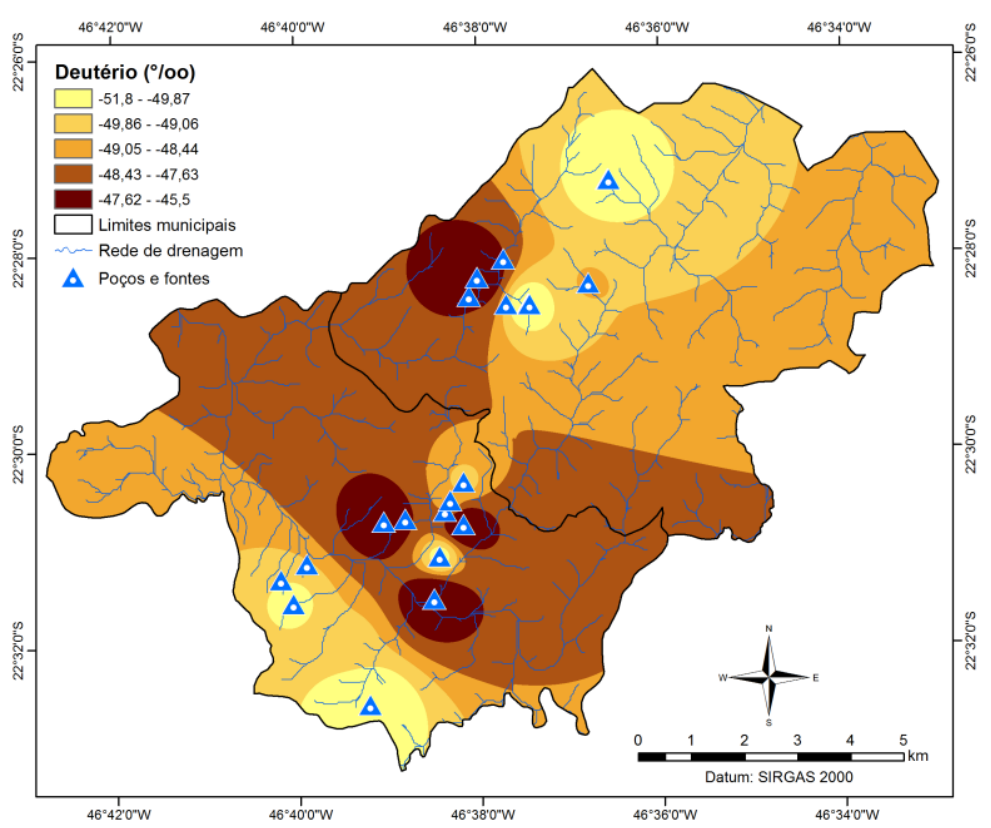

Figura 7: Mapas de Isótopos de hidrogênio (adaptado de Yoshinaga, 1990).

Sendo que as concentrações dos diferentes poços e fontes, indicam que as águas das fontes santa clara, levíssima 1 e 2 e Líndoia provém de recarga direta, enquanto as demais sofrem evaporação e enriquecimento de isótopos no durante sua infiltração e circulação e não refletem os valores destes isótopos nas chuvas locais como reflete gráfico (figura 7) que mostra a relação entre $\delta$ 
$\mathrm{O}^{18}$ e $\delta^{2}$ das águas de fontes e poços tubulares em função das retas meteóricas mundiais (YOSHINAGA, 1990).

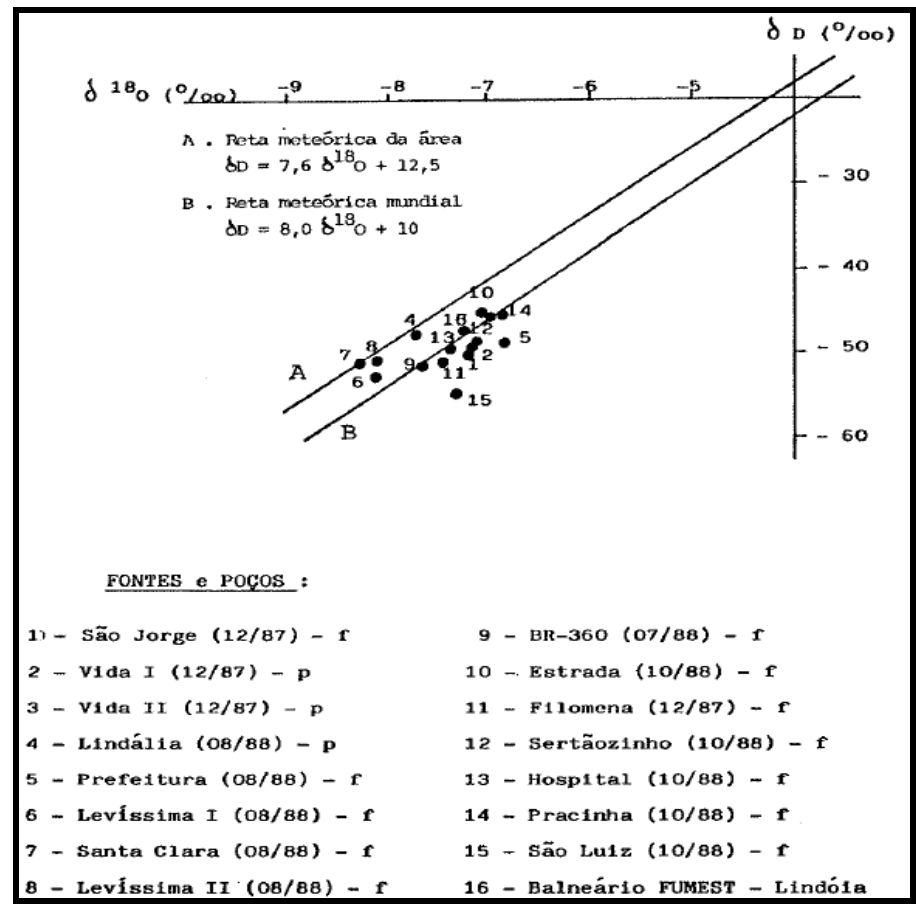

FIGURA 8: Relação entre $\delta \mid \mathrm{O}^{18} \mathrm{e} \delta^{2}$ das águas de fontes e poços tubulares em função das retas meteóricas mundiais

Fonte: Yoshinaga, (1990).

\section{4 - CONCLUSÕES}

Os isótopos possibilitam avaliar as características das águas, possibilitando datar sua idade e avaliar a influência do meio ambiente sobre as águas meteóricas. Na região do Circuito Paulista das Águas, as águas são pouco mineralizadas, e são classificadas como Bicarbonatadas mistas ou cálcicas. As águas da região apresentam potabilidade, porém devido seu fluxo rápido e tempo de residência baixo, os condicionantes ambientais devem ser constantemente avaliados, para evitar contaminantes.

\section{AGRADECIMENTOS}

CAPES, FAPESP

\section{5 - REFERÊNCIAS}

BRADY, N.C. \& WEIL, R.R. Elementos da natureza e propriedades dos solos. Porto Alegre, Bookman, 2013. 685p.

BRASIL. Empresa de Pesquisa Energética. Balanço energético 2013: Ano base 2012. Ministério de Minas e Energia, 2013. 283p.

CARVALHO, N.O. Hidrossedimentologia Prática. 2.ed., Rio de Janeiro, Interciência 2008. 600p. 
CLARK, I.; FRITZ, P. 1997. Environmental Isotopes in Hydrogeology. New York, CRC Press. $328 \mathrm{p}$.

DAEE; Departamento de Águas e Energia Elétrica. Mapa de águas subterrâneas do Estado de São Paulo : escala 1:1.000.000. São Paulo, 2005.

FETTER, C.W. 1994. Applied hydrogeology. McMillan College Publ. Co. New York, 680p.

FUNDAÇÃO SOS MATA ATLANTICA \& INSTITUTO NACIONAL DE PESQUISAS ESPACIAIS - INPE. Atlas dos Municípios da Mata Atlântica - período 2011-2012, Anexo 1. São Paulo, INPE, 2013. 100p.

HASUI, Y. A Grande Colisão Pré-Cambriana do Sudeste Brasileiro e a Estruturação Regional. Geociências, São Paulo, v. 29, n. 2, p. 141-169, 2010.

IAC et al. Mapa pedológico do Estado de São Paulo. São Paulo, Governo do estado de São Paulo, 1999.

IAEA - International Atomic Energy Agency. Environmental Isotopes in the hydrological cycle. Principles and applications, 2001 541p.

MADRUCCI V.; TAIOLI F.; ARAÚJO C.C. Análise integrada de dados de sensoriamento remoto, geologia e geofísica no estudo de aquífero fraturado, Lindóia - SP. Revista Brasileira de Geofísica v. 23, n. 4, p. 437-451, 2005.

MADRUCCI V; TAIOLI F.; ARAUJO C. Groundwater favaorability map using GIS multicriteria data analysis on crystalline terrain, São Paulo state, Brazil, Journal of hidrology, v.357, p 153$173,2008$.

MORGAN, R.P.C. \& NEARING, M.A., eds. Handbook of erosion modeling. West Sussex, Wiley Blackwell, 2011. 352p.

NEGÃO S. Determinação dos isótopos naturais de rádio de meias-vidas longas, ${ }^{226} \mathrm{Ra}$ e ${ }^{228} \mathrm{Ra}$, em águas minerais utilizadas nos balneários de caxambu (MG) e águas de Lindóia (SP). Disssertação de mestrado.2012.71 p.

SILVEIRA E.G.; BONOTTO D.M. Comportamento hídrogeoquímica dos isótopos de urânio em Águas de Lindóia (SP) Brasil. Revista brasileira de Geociências, v.23, n.3, p.165-172,1995.

SILVEIRA, C S; SILVA JÚNIOR G. C.. O uso de isótopos ambientais em estudos hidrogeológicos no Brasil: uma resenha crítica. Anu. Inst. Geocienc., , v.25, p.25-43, 2002.

SPAROVEK, G.; VAN LIER, Q. J.; DOURADO NETO, D. Computer assisted Köppen climate classification: a case study for Brazil. International Journal of Climatology, Chichester, v. 27, n. 2, p.257-266, 2007. 
UNFPA, Fundo de Populações das Nações Unidas. Relatório sobre a Situação da População Mundial 2012. Nova York. ONU, 2012. 137p. Disponível em http://www.unfpa. org.br/ Arquivos/swop2012.pdf. Acesso em: 05 abril 2013.

YOSHINAGA S. Estudos hidrogeológicos, hidrogeoquímicos e isotópicos das águas minerais e termais de Águas de Lindóia e Lindóia, SP. Dissertação de Mestrado. São Paulo - USP, 1990. $113 \mathrm{p}$. 